\title{
9
}

\section{Embodied Selfhood}

\author{
An Ethnographic Exploration \\ of Alzheimer's Disease
}

PIA C. KONTOS

\begin{abstract}
A
zheimer's disease is regarded as the most bewildering and frightening condition facing the aging population in the twenty-first century (Schroeder et al. 1990) and represents a much feared stigmatizing label that carries with it the force of a sentence of social death (Robertson I99I). As Herskovitz notes, senility is characterized as "monstrosity" by the lay media with "clichéd metaphors and representations in which Alzheimer's is characteristically drawn in colourfully dramatic terms that paint vividly disturbing images" (I995, I52-I53). Alzheimer's is described as a living death, a never ending funeral, and a private hell of devastation.

The source of the fear is found in much of the Alzheimer's literature in which individuals with dementia are said to experience a steady erosion of selfhood as a consequence of the cognitive deficiencies that lie at the core of the illness (Cohen and Eisdorfer I986; Mills and Walker 1994). As Fontana and Smith state, with advancing Alzheimer's, what is actually happening is that the self is becoming "increasingly devoid of content" (I989, 36). It is, they say, "unbecoming a self." Others echo these sentiments by describing Alzheimer's as a disease that "eradicates the essence of the person" (Dalziel 1994, I407), as a process of "drifting towards the threshold of unbeing" (Kitwood and Bredin I992, 285). Thus, while Alzheimer's is usually described and analyzed in terms of the cognitive dysfunction it produces, there is, as well, a presumed existential outcome: the loss of self with the concomitant erosion of individual agency (Davis 2004; Herskovitz I995; Ronch I996).

This presumed loss of selfhood is itself a product of the Western assumption that status as a full human being is completely dependent upon cognition and memory, both of which become impaired with advancing Alzheimer's:
\end{abstract}


"Alzheimer's disease represents the loss of all those qualities by which we have come to define our humanness" (Robertson I99I, I43). This representation of personhood is itself the legacy of Western philosophy's tendency to split mind from body and to position the former as superior to the latter. In contrast to the Cartesian mind/body dualism, in which human meaning and selfhood are attributed to the mind, I propose to integrate Maurice Merleau-Ponty's (I962) radical philosophical reconceptualization of perception and Pierre Bourdieu's (I977, 1990) sociological exploration of the logic of practice, yielding a theoretical framework that captures the existential immediacy of the body as well as its interrelationship with culture and history (Kontos 2003).

The central aim of this chapter is to explore how this proposed theoretical framework that advocates the irreducibly embodied nature of agency brings a new and critical dimension to the challenge of the presumed loss of personhood in Alzheimer's and, more broadly, to the Western representation of personhood that hinges on cognition and memory. To do so, I will analyze, from the perspective of embodiment that I advocate here, findings drawn from an ethnographic study of an Alzheimer's support unit of a Canadian home for the aged.

\section{The Setting}

Chai Village is an Orthodox Jewish facility that provides long-term care for 472 residents; the majority suffer from Alzheimer's dementia and a small minority have vascular dementia. ${ }^{1}$ Approximately eighty residents reside on each floor, the majority of whom are women ( 82 percent), with the average age of all residents being eighty-eight years.

The present study was conducted on one of the floors that provide support for residents suffering from Alzheimer's dementia. Of the seventy-nine residents on the floor, thirteen participated in the study, three men and ten women, all of whom are Jewish and of Eastern European descent and whose cognitive impairment ranges from moderate to severe (39 percent were severely cognitively impaired). ${ }^{2}$ Because of cognitive impairment, informed consent to participate was provided by proxy. Participant observation took place over the course of eight months, approximately eight hours a day, three days a week, during scheduled program activities and mealtimes and when participants engaged in unscheduled activities such as walking or sitting in the hallways.

The focus of my analysis will be a series of occurrences I observed at Chai Village that are presented here in the form of vignettes in order to fully contextualize the events described. Also, where appropriate, I will draw upon other instances from my ethnographic data as well as characteristics of individual participants in this study in order to highlight pertinent points of my analysis. 


\section{Appearance}

There is among most female residents the desire to retain a sense of feminine beauty. There is a constant concern with self-presentation such as when Anna insists on putting on lipstick before going to social programs or when Frances places her hand on her chest, preventing her blouse from touching her food as she leans over her plate. ${ }^{3}$ The following scene vividly captures Molly's attention to social grace and neatness. It is her frailty and inability to feed herself that makes Molly's attention to appearance all the more significant.

\section{String of Pearls}

Molly's wheelchair seemed enormous in contrast with her thin, wizened body. Her legs had severely atrophied, giving the impression of two-dimensional forms. Were she able to stand, she would be no more than five feet tall. Her face was heavily wrinkled but the skin was soft, resembling that of a peach. Her hair was uniformly white, accentuating her China blue eyes. The backs of her hands were the most vivid testament to the near century she had lived. The skin was thin, revealing a network of bones and purple veins. Her hands shook as if powered by an invisible gentle motor.

Despite her withered appearance, there was an indescribable elegance to Molly. I noticed this in watching her as she was brought to the dining room. Once her wheelchair was positioned at the table, a bib was fastened around her neck. Molly then carefully unfolded her napkin and placed it on her lap. Even though the use of the bib made the need for a napkin redundant, she nonetheless insisted on observing this table etiquette.

As a health care aide was feeding her, cereal dribbled from Molly's mouth and coursed down her chin. When the aide tried to give her another spoonful, Molly wrinkled her forehead and gently pushed the woman's hand away. Molly then lifted her bib to her mouth to wipe away the cereal. It was only after her chin was clean that she accepted another spoonful. One might expect indifference from a woman who had lost the ability to feed herself, yet Molly's insistence on adhering to the social graces and her attention to neatness suggested a strong and continuing presence in the world.

She closed her eyes slowly and opened them again, releasing a deep sigh. She then looked around the table as if for the first time noticing that there were others seated with her. She patiently waited to make eye contact with each person to acknowledge his or her presence. Then reaching her wavering hand to the back of her neck, she struggled to pull something from underneath her bib. Extending her arm appeared to cause her pain and discomfort, yet she persisted. She eventually revealed a string of pearls that she was wearing and that had been covered by her bib. She allowed the pearls to pass through her long, 
slender, perfectly manicured fingers, placing the necklace ever so delicately atop her bib. With this simple gesture, Molly emerged from her world of decrepitude, incontinence, dementia, and helplessness.

\section{Creativity and Self-Expression}

There is a rich diversity of social activities at Chai Village. Among the regular weekly events is the creative arts program, a popular activity among the residents that offers ceramics, silk-scarf painting, drawing, knitting, crocheting, needlepoint, and beading. The following vignette describes Ethel's ability to sew in the absence of any cognitive awareness of her ability to do so.

\section{Knowing Hands}

Sitting next to Edna, I admired the pink sweater she was wearing. She looked radiant. As I complimented her on the sweater, she looked down at it, perhaps to remind herself of what she was wearing, and announced, "I make all my sweaters." When she looked up at me she exuded a great sense of pride as she smiled and lifted her chest in confidence. Ethel, who was sitting across from us, was listening to our conversation. Eager to include her, I asked if she still did needlepoint. Ethel had numerous colorful canvases decorating the walls of her room, all created by her own hand. Leaning forward in her chair, she asked in a high-pitched voice, "What? I did that before?" Her frown and downcast eyes signaled her confusion. Edna looked at Ethel in utter disbelief and said, "You don't remember if you worked with your hands?" She wildly gestured as though she were weaving. Sinking back into her chair, Ethel shook her head and with a hint of melancholy said, "I don't remember." She then fell into an embarrassed silence and lowered her head.

Several days later I accompanied Ethel to the creative arts program, as she was on a list of residents who participated in this activity. Mrs. Anderson (the coordinator of the program) greeted Ethel with familiarity, confirming that Ethel had in fact participated there before. She showed Ethel to the table and brought her a canvas that had already been stitched with several rows of yarn. Attached to the top of the canvas was a piece of masking tape with Ethel's name written on it. Ethel looked at Mrs. Anderson with concern and said, "I don't know how." In a kind, understanding voice, Mrs. Anderson reassured Ethel by saying, "You don't have to know, but we like you to try." In great distress, holding her hands out with her palms facing upward, Ethel replied, "I cannot." As if it were part of their routine exchange, Mrs. Anderson began stitching a row, to demonstrate how it was done. Ethel watched as though she were observing something foreign. Before reaching the end of the row, Mrs. Anderson encouraged Ethel to take the needle and continue. Then, as if the needle placed be- 
tween her fingers had triggered a forgotten ability, Ethel began to stitch. Mrs. Anderson seemed pleased and moved on to assist another resident.

I stood and watched Ethel with amazement. Holding the canvas in one hand, she passed the needle through with the other and in two swift movements the stitch was completed and she began the sequence once again. The rhythm with which she was weaving demonstrated a proficiency that was in striking contrast to her previous proclaimed inability. She very quickly completed the row and, without hesitation, took a fresh piece of yarn in her hand, licked one end, and, pinching it between her thumb and index finger, attempted to thread the needle. The yarn splintered and she was unable to push it through. She licked it once again, and pinching the end several times, she succeeded in passing it through the eye of the needle. She looked up at once, and as our eyes met, she raised the threaded needle in triumph.

\section{Ritual and Ceremony}

As noted earlier, all the residents of Chai Village are Jewish, and Jewishness is a vital, integral part of their daily life. There are two rabbis on staff at the facility, daily synagogue services are offered on site, a centerwide kosher food policy is in place, and there are Sabbath and other holiday observances. The following scenes capture the enactment of different ancient, well-known ritual gestures related to the holidays of Simchat Torah and Hanukkah. Each ritual involves certain symbols that pertain to the Jewish home and family, as well as customs that are physically enacted, and are thus profoundly corporeal experiences.

\section{Prayer}

Simchat Torah is one of the most widely celebrated rituals in the Jewish faith. It is the day of celebration for the gift of Torah, the five books of Moses, whose wisdom enables the Jewish people to know how to live close to God. The Torah scrolls are the holiest of objects and are carefully stored in a curtained altar. Each scroll is handwritten in Hebrew on parchment and then rolled onto two poles that are topped with silver handles. Every Saturday, the appropriate scroll, as determined by the Hebrew calendar, is brought out during the service and unrolled so that a portion of it can be read aloud. The reading of the Torah is seamless; once completely read, it is immediately reread. The rituals of Simchat Torah revolve around a continuous cycle of Torah readings.

On Simchat Torah the synagogue at Chai Village rang out powerfully in hymn. The service leader circled the bimah (the central platform from which the Torah is read) while holding the Torah and reciting a short prayer responsively with the congregation. Following Orthodox custom, women prayed in a gallery to the side of the main body of the synagogue, where the men prayed. All had 
covered their heads in one way or another-the women with hats, scarves, and even a small swatch of fabric; the men with yarmulkes (skullcaps) that were made of paper, cloth, or beads. The men also covered their shoulders with a tallis (fringed blue-and-white prayer shawls). My attention was drawn to the center of the synagogue, where the men prayed with intensity and passion. Among the participants stood Jacob.

Jacob would often chastise residents who, because of their dementia, would create disruption. Ironically, his own advanced demented state had limited his verbal expression to the use of single words. Jacob would frequently call other residents names in Yiddish such as meshugener (crazy person), am-ha-aretz (ignorant individuals who are noisy and continually creating disturbances), kvetch (a person who always complains), and fressers (people who eat like animals). Although these words would be shouted in single utterances, all are powerful summary interpretations of his perception of the behavior of the targeted individuals. When he was not using single words, Jacob's speech was incoherent, which enraged him. So intense were his outbreaks of rage under those circumstances that staff would have to escort him out of the room.

Jacob moved his lips with the chants of the leader of the service. I watched as he swayed deeply, stepping forward and back, bowing and striking his chest with clenched fists, as is commonly done in Jewish prayer. He was energetic and forceful. Suddenly there was a disturbance in the women's gallery that silenced the congregation. A woman in a wheelchair had mistakenly taken the place of a woman who had just returned from the washroom. The leader of the service paused, and all the congregants shifted uneasily in their seats as the woman shouted that she wanted her place back. Jacob turned to face the woman in the wheelchair-her body twisted and crimped from the effects of a stroke-and in a string of incoherent speech, he yelled at her, shaking his index finger. He was visibly agitated; his body shook with anger. A porter quickly moved to resolve the conflict in the women's gallery and a health-care aide approached Jacob to escort him out of the synagogue. His uncontrollable rage left little choice. However, just as the aide approached Jacob, the leader resumed the service, belting out a prayer. Jacob's response was immediate. His rage was instantly quashed. He fell into a reverent silence, closed his eyes, and resumed his fervent bodily movement of prayer.

Jacob was once again focused on the service. The leader held a Torah scroll and circled the interior of the synagogue, followed by honored members of the congregation, who also held the scrolls. It is customary for synagogue members to reach out and touch the passing scrolls, raising their fingertips to their lips in a kiss, displaying respect for the Torah. Jacob joined in the celebration with this gesture of respect for the sacredness of the Torah. After the procession of Torah bearers circled the synagogue, the leader broke out in joyous song and all the 
congregation joined in singing and dancing. In the center of the synagogue the men formed a circle and danced around those who held a Torah scroll. The women formed a circle of their own in their separate gallery and similarly lost themselves in ecstatic fervor. Jacob hesitated for a moment, looking around the room smiling shyly, as if embarrassed about expressing enthusiastic joy in public. But he had little more than slight hesitation in regard to the Torah, twisting his shoulders and hips and snapping his fingers in the air. Despite his initial hesitation, he knew from previous experience that it was appropriate, that his movements and gestures suited the occasion.

It is Orthodox custom for the men to be honored with an aliyah (the act of being called up to the bimah), in order to say the blessing following the reading of the Torah on Simchat Torah. When the dancing quieted, each male congregant was called up to the bimah to say the broche (blessing). When Jacob was called forward, he moved firmly and with upright posture to the platform. Without any prompting, he leaned his body over the Torah and recited the prayer with absolute coherence and precise pronunciation. The visiting wife of another resident was seated next to me and, clearly familiar with Jacob's dementia, said, "You can forget everything but you never forget the broche over the Torah." Jacob was unable to put a sentence together, but standing before the Torah he was in full command.

\section{The Way Through}

Hanukkah, an eight-day Jewish holiday, is celebrated in remembrance of the rededication of the Temple of Jerusalem after its defilement by Antiochus of Syria. This holiday is marked by the lighting of the menorah, a candelabra containing nine separate candles. The lighting of the menorah commemorates the miracle of Hanukkah, namely, that following the destruction of the Temple of Jerusalem, the cruse of oil that was found in the ruins of the temple and thought to contain only enough oil to burn for one day, in fact burned for eight. On each day of Hanukkah, after sundown, the middle candle is used to light another candle, representing the day of the holiday that has passed. This continues until the eighth day, when all candles on the menorah are lit.

The eighth day of Hanukkah is considered to have special significance as the culmination of the holiday, the day when the menorah burns most brightly. It was on this day that a concert and party were arranged for the residents of Chai Village. The planned festivities attracted more residents than the number that the social programs normally brought in. That the day was set apart was clear from the residents' appearance: the women held purses that were perfectly preserved from earlier decades and wore their best dresses and jewelry. Gold necklaces and bracelets studded with diamonds and pearls were worn in 
place of the usual beaded jewelry that had been made in the creative arts program. Scarves and colorful hats brightened the women's faces. Men wore tidy suits over frayed but neatly pressed shirts.

The concert began with piano music and a strong alto that filled the room with Yiddish song. As I stood listening and watching, I noticed Dora. Her eightyfive years had been kind to her face, leaving a smooth and creamy complexion. Her lips were full and pink, and her eyes unclouded by cataracts or glaucoma. The backs of her hands were blotched with brown spots and her fingers crimped by arthritis. Even Dora, within her limited financial resources, rose to the occasion by wearing a faded floral polyester dress with an old green heavy-knit cardigan-sweater set that matched. Her feet, resting on the pedals of her wheelchair, looked painful as her calluses and bunions protruded from her plastic sandals.

Somehow, while sitting in her wheelchair, Dora was dancing. She created a sense of fluidity and abandon, moving her arms above her head elegantly and delicately wiggling her fingers while slowly lowering her hands to each side of her wheelchair. Dramatically tossing her head back, she extended her arms above her head as though performing an arabesque. So choreographed were her movements that I wondered if she was reenacting a performance from another time. When the song finished, applause erupted in appreciation of the singer and pianist, and Dora moved her upper body forward in her chair as if to take a bow for her own performance.

Jelly doughnuts, brought out by staff and volunteers, were served to the residents on plastic plates with a napkin. Dora ate her doughnut as she continued to listen to the music. Licking the jelly from her fingers, she moved her head from side to side. With her hands busy with the doughnut, she struggled to stretch her legs out in front of her. Her swollen feet looked almost delicate as she gently brought her toes and then her heels together, alternating these movements to the rhythm of the music.

Following the concert, there was to be a ceremonial lighting of the menorah. As it was the eighth day of Hanukkah, all eight candles would be lit. Mrs. Allen, the program coordinator, invited a resident from the audience up to the menorah, located at the front of the room on a small table that had been carefully covered with a white cloth. Mrs. Allen lit the candles and the resident recited the appropriate blessing while bowing her body forward over the small flames. Although Dora watched with intense interest from across the room, it was difficult to determine how much of the ritual she was able to see. The lighting of the menorah marked the end of the program, at which point the staff and volunteers began the task of taking the residents back to their rooms.

A health-care aide approached Dora, released the brakes of Dora's wheelchair, and announced, "It's time to go." Dora immediately clutched the woman's arm and shook her head vehemently, indicating that she did not want to go. 
Dora's insistence on staying was inexplicable amid everyone's eagerness to return to their rooms. The aide did not have time to question Dora's resistance, for she was distracted by another resident who had considerable difficulty in walking and required immediate support. I watched Dora as she struggled to make a path for herself through the crowd, manually navigating her wheelchair around walking aides, other moving bodies, and chairs. Following a slow and laborious process, she finally reached her destination, the table where the menorah stood in glorious full flame.

Dora unfolded the napkin she had used when eating her jelly doughnut and, ensuring that the jelly side was facing upward and not touching her hair, she placed it with utmost care atop her head. She then held her palms up to the menorah, embracing the warmth of the candles. I was close to her but she did not see me. She then raised her hands to her face, covering her eyes, and prayed privately. Dora had seemingly slipped into another time, subsumed by an inner experience that was strangely sheltered from the ongoing commotion in the room. Tears streamed through her fingers. When she removed her hands she looked up at me and smiled with a transformed visage. I saw in her face a deep pleasure, and I smiled at her. Dora removed the napkin that had served as her head covering and smoothed her soft white hair. The aide who earlier had tried to take Dora to her room returned for her. This time Dora did not resist. Dora's hands were gently clasped in her lap and her face was peaceful as she left the room.

\section{Discussion}

The ethnographic data here clearly demonstrates that the residents of Chai Village exhibited selfhood in the face of even severe cognitive impairment. It is a notion of selfhood that speaks of a complex interrelationship between the primordial and the social characteristics of the body, all of which reside below the threshold of cognition, grounded in the prereflexive level of experience, existing primarily in the corporeal. My discussion in this chapter will suggest that selfhood resists the ravages of Alzheimer's disease precisely because it resides in corporeality.

I turn now to Merleau-Ponty's analysis of motility as basic intentionality in order to begin to understand the role that the body plays, at the most fundamental level, in selfhood, as expressed by the residents of Chai Village.

\section{The Primordial Sources of Selfhood}

Merleau-Ponty argues that embodied consciousness, which he refers to interchangeably as "embodied significance" or "nonrepresentational" and as "basic intentionality," is a fundamental level of existence that does not involve a cognitive form of consciousness. Merleau-Ponty's basic intentionality is the body's concrete, spatial, and prereflective directedness toward the lived world. The 
prereflective moving body is in and of itself intentional by virtue of being naturally invested with a certain perceptual significance, a bodily know-how or practical sense. He argues that the body in movement is not limited to submitting passively to space and time, for the body actively and intentionally takes them up in their elemental significance. In Merleau-Ponty's words, "[A] system of possible movements radiates from us to our environment” (I964, 5), giving us at every moment a practical and implicit hold on our body, a hold that situates us as subjects perceptually, linguistically, and through motor activity. I understand selfhood as inhering in what Merleau-Ponty describes as corporeal and nonreflexive intentionality, and as such, it is my claim that selfhood must be understood as being enacted in the actual movements of the body.

Within this "system of possible movements," the body possesses, according to Merleau-Ponty, a coordinating power in relation to itself, what he refers to as the primary perceptual level, which is prior to any explicit act of intellection on our part. He cites the following example to illustrate the prereflective nature of the coordination of visual, tactile, and motor aspects of our body: When bitten by a mosquito, we do not need to look for the part of the body where we have been bitten. We find it straight away by reaching for the itchy spot on our phenomenal body. For us there is no question of locating it in relation to axes of coordinates in objective space. In the natural system of our own body, we experience a direct relationship between our hand as an instrument of scratching potentiality and the part of our body that has been bitten as a spot to be scratched. The whole operation takes place, according to Merleau-Ponty, in the domain of the phenomenal (I962, IO5-IO6).

Similarly, it can be seen in the example of Ethel's stitching, in that when the needle and thread were placed between her thumb and finger, she did not need to look for her hands or her fingers when she began to sew, because they are not objects to be discovered in objective space. The task to be performed, the stitching, immediately elicited the necessary movements from Ethel as she took hold of the objects, assimilating their structure into her body, without any calculation on her part. Ethel's example makes apparent the spontaneous method of perception, what Merleau-Ponty describes as a kind of living system of meanings, which makes the concrete essence of the object immediately recognizable. As soon as Ethel took hold of the needle and thread, these objects meant something, without the meaning having to be established through cognition. In other words, there was an immediate familiarity with, and an effortless use of, the needle and thread.

Ethel was able to sew without any cognitive awareness of her ability to do so. The disjunction between cognitive impairment and the coherent expression of talent or skill draws attention to Merleau-Ponty's example of one who knows how to type without having to think out the location of each letter on the keyboard (I962, I44). Even more than this, though the typist does not know where the keys 
are in a reflective sense, he or she-to make any attempt to provide a reflective and discursive account of the keyboard layout-would have to imagine typing in order to see the direction in which his or her fingers moved to hit the appropriate keys. Knowledge of typing, Merleau-Ponty argues, is in the hands and manifests itself only when bodily effort is made and cannot be articulated in detachment from that effort.

Merleau-Ponty does not intend for knowledge to be understood in an intellectualist fashion in cases in which it would be associated with the supposedly self-transparent activities of a reflexive subject. Indeed, the kind of knowledge of the keyboard that the typist has is a practical, embodied knowledge, quite remote and distinct from discursive knowledge. Knowledge, as Merleau-Ponty understands it here, is the capacity for acting, the know-how belonging to a subject whose primary relation to the environment is that of prereflective, active, and practical involvement. He speaks of how the perception of our body functions as a logic lived through that does not rely upon reflective-discursive thought, and thus the meaning of that which is perceived becomes fully elucidated only through bodily movement (I962, 49). In the absence of practical involvement, stitching did not register any significance for Ethel, as evidenced by her protest of “I don't know how." Ethel's knowledge of sewing was forthcoming only when she herself took hold of the needle, thus highlighting precisely the distinction that Merleau-Ponty draws between intellectual and practical significance. The relevance of practical significance, which for my discussion of selfhood has the same meaning as nonrepresentational intentionality, is that this primordial level provides the foundational structure for selfhood. In this sense, Ethel's stitching renders visible how selfhood resides in, and is manifested through, the ways of the body. Conceptualized in this way, selfhood is supported by and emanates from the existential expressiveness of the body

However, there is an obvious difference between the example of Ethel's stitching and Merleau-Ponty's example of the typist. The typist, though unable to describe the layout of the keyboard, is fully aware of his or her ability to type. Ethel, however, claims to be unable to sew, demonstrating a lack of cognitive awareness of an ability that she in fact possesses. Despite this difference, the relevance of Merleau-Ponty's example of typing to my analysis of Ethel's sewing is that in both instances, bodily movements are not dependent upon cognition in order for the necessary tasks to be performed, but rather rely upon what Merleau-Ponty refers to as motor intentionality. Ethel's ability to sew is guaranteed by her body itself as a "motor power," a "motor project" (I962, IIO), in the absence of which the instruction to sew, as given to Ethel by the coordinator of the creative arts program, would remain unfulfilled. This is to say that Ethel's ability to sew is completely dependent upon her having incorporated the meaning of the needle and thread and the rhythm of stitching into her bodily 
schema, just as the typist incorporates the keyboard space into his or her bodily schema.

Embodied selfhood can be further explored through additional examples of basic bodily movement. In Chai Village, when Molly reached behind her neck to pull her pearls from beneath her bib, she "knew" where her hand was and how far and at what angle she had to reach to grasp the pearls. Similarly, when Dora performed her seemingly choreographed dance at the Hanukkah party, she, like Molly, desired a certain outcome of her actions, and the necessary tasks were spontaneously distributed in the appropriate parts of her body. Their movements were perfectly suited to the exigencies of the circumstances without Dora's having to think of how to make them or to articulate reflectively the principles upon which their actions were based. Neither Molly nor Dora launched their bodies into blind attempts to perform an action; every movement was inextricably movement and embodied selfhood. That is, selfhood can be observed in movement where movement itself attests to the hold the residents have on the general synthesis of their bodies, a hold that emanates from the primordial unity of the body.

\section{The Primordial Depths of Sociability}

Chai Village residents are not operating in their own private worlds. On the contrary, they are participants in a common world and communicate with one another. In performing social interactions, in order that we understand the words of another person, a vocabulary and syntax must be previously known. Merleau-Ponty argues, however, that words do not do their work by arousing representations associated with them (1962, I83). Language certainly has an inner content, but the meaning of words is not contained in the words themselves such that their intelligibility is finitely self-subsistent, but rather emerges in the flow of intercourse. As Merleau-Ponty argues, it is in the context of interaction that words assume their conceptual meaning, grasped by a kind of deduction from gestural communication (I79). Thus, even with language, Merleau-Ponty detects certain existentialist tendencies, underscoring the primacy of embodiment in speech itself.

Merleau-Ponty's intention is to restore to the act of speaking its corporeality through an analysis of the embodiment of speech in the lifeworld. MerleauPonty's argument that speech is a gestural system is perhaps most apparent where no linguistic meaning at all is conveyed by speech itself. This is so because in such instances we are still able to communicate with one another by virtue of the expressive dimensions of the gesticulating body, which are fundamental to communication in human interaction. The following exchange between Anna and Abe is noteworthy.

Abe sat down in the dining room and shouted, "Bupalupah." Anna twisted around in her chair so that she could see Abe (his table was behind hers). Abe's 
face opened up. His eyes grew wider, his mouth eased into a broad smile, and he shouted, "BrRRRrRr!" with a rising and then falling pitch. Anna imitated him, shouting back, "BrRRRrRr!" following the same change in pitch. Abe then shouted, "Bah!" and paused while looking at Anna. Anna shouted, "Shah!” and then waited for Abe's response. Abe shouted, "Bah!" and Anna, "Shah!” as they established a repetitious pattern of exchange. Anna eventually turned back around in her chair, with her back to Abe. Abe shouted, "Bupalupah!" as if wanting to initiate another exchange with Anna, but instead of responding verbally, she raised one arm above her head and lowered it in a swift motion with a sharp flick of her wrist. With this gesture, she terminated their interaction, and they both began to eat their breakfast quietly.

Even when speech is incoherent and void of linguistic meaning, in face-toface interaction there is a smooth and appropriate alternating pattern of vocalizing, as well as gesticulating, back and forth. With the utterance of only "Bah," "Shah," "BrRrRrR!" and "Bupalupah," Abe and Anna were able to communicate without any recourse to intellectual interpretation. There was a fittingness and a meaningful relationship between the rise and fall of their pitch, their pauses, and their postural shifts. Their gestures had a melodic flow and fluent form, rather than appearing as a composite of bodily movements strung together in a mechanical way. What this example illustrates is Merleau-Ponty's argument that communication dwells in corporeality or, more specifically, in the body's capacity to gesture $(1964,7)$. Because of the fact of speech impairment, the force of their speech acts derived not from semantic content but rather from the meanings that their bodies directly indexed. Communication, Merleau-Ponty argues, is a continuation of the corporeal schema. As such, it is my claim that selfhood persists in and through the body's power of natural expression, that is, the body's inherent ability to apprehend and convey meaning.

\section{Limitations of Merleau-Ponty's Perspective}

We saw with Merleau-Ponty that the body naturally lends itself to movement and gesture because of the body's primordial essence, which functions as a form of generality, giving embodied consciousness an impersonal quality. However, there is a certain style or content to bodily movements and gestures, the source of which cannot be attributed solely to a primary level of signification. Bourdieu's concept of habitus is pertinent here because unlike the generality of the primordial, Bourdieu addresses the sociocultural sources of bodily practices.

Habitus consists in dispositions, schemata, forms of know-how and competence, all of which function below the threshold of consciousness, enacted at a prereflective level. As Bourdieu states, "The schemes of the habitus, the primary forms of classification, owe their specific efficacy to the fact that they function below the level of consciousness and language, beyond the reach of introspective 
scrutiny or control by the will" (I984, 466). Wacquant (I992), perhaps Bourdieu's best commentator, has noted that Bourdieu is clearly drawing on Merleau-Ponty's idea of the body as the source of practical intentionality and of intersubjective meaning grounded in the preobjective level of experience. The body is treated as having a "generative, creative capacity to understand" (Wacquant 1992, 20) - a kind of corporeal awareness-a practical reason, with reason existing primarily in corporeal ways. However, with the concept of habitus, Bourdieu takes us beyond the elements of essentialism and the subjectivist grasp of practical sense in order to investigate practice in the context of the social genesis of its conditions of operation. Thus, Bourdieu's exploration of competence, know-how, skill, and disposition moves him into the sociocultural horizon in which, according to Bourdieu, bodies assume their embodied significance.

It is my argument that selfhood, in addition to having a primordial source, consists in the dispositions and generative schemes of habitus and thus, in the same way that dispositions are embodied and materialize in practice, selfhood is embodied and manifested in a socioculturally specific way of being in the world. I will continue to explore communication in the following section but with a shift in focus to the sociocultural sources of selfhood.

\section{Communication in Sociocultural Context}

Bourdieu's argument that cumulative exposure to certain social conditions instills in individuals an ensemble of durable and transposable dispositions is evident when we consider that Chai Village residents have a habitual state, "a tendency, propensity, or inclination” (Bourdieu 1977, 2I4nI), to gesture in a particular manner. Voice, facial expressions, and body movements were distinctive and predominant manifestations of selfhood in communication among my participants. When the residents of Chai Village interacted with one another, so identifiably Jewish were their intonation patterns and nonverbal forms of communication that a person of Jewish heritage did not need to know that Chai Village is a Jewish facility to recognize instantly that the residents were Jewish. Following Bourdieu, we could say that their Jewishness is actually embodied in their arms, hands, feet, and head underscoring the essence of habitus, which is the embodiment of culture-specific conditions of primary socialization. ${ }^{4}$ I would add that selfhood resides in the embodiment of culture-specific conditions of primary socialization, and thus, Jewishness is a manifestation of my study participants' selfhood. Typical Yiddish gestures include flinging one or both hands in front of the body in a swift downward motion, with elbows close to the body and turning head away slightly; holding hands with palms facing outward, elbows kept within a very narrow area, close to the body, while turning the head all the way to one side, lifting the opposite shoulder slightly. Efron (I972) has described the various aspects of such gestures and argues that East- 
ern European Jews who have maintained their Old World traits or mannerisms have a propensity to accompany their speech with lively bodily motions, a propensity, Bourdieu would claim, that is determined by their cultural heredity.

In addition to gestural communication, discursive expressions equally reveal a dispositional character that emerges from the internalization of a sociocultural environment through the primary experiences of the body. For example, the Yiddish language has an expressiveness that is manifested in the rhythm of speech. There was a great deal of emotion in the highs and lows of my participants' voices. As the sounds went up and down in melodious directions one could feel the words as much as hear them. One is not born with a culturally distinct intonation pattern but acquires it "by the childhood learning that treats the body as a living memory pad" (Bourdieu I990, 68). The way my participants spoke and used their bodies to express themselves are examples of cultural aspects of selfhood "given body, made body" (69; emphasis in original).

\section{Ritual and Ceremony}

Jacob's prayer at the bimah and Dora's before the menorah were ethnic ritual gestures that captured a sacred moment by bringing the past into the present. However, I would argue that such rituals are not a matter of bringing into the focus of consciousness a picture of the past. Reenacting rituals that were part of one's early childhood is not a matter of delving into the past through a cognitive operation. Following the logic of the concept of habitus, these rituals underscore the active presence of the past in the body itself. We could say that the rituals are "embodied history, internalized as a second nature and so forgotten as history" (Bourdieu I990, 56). "Embodied history" here suggests that past experiences persist in the body in the form of transposable dispositions that collectively function as a matrix of perceptions and actions. They are embodied in the sense that the memory of them is not confined to the brain but is actually encoded in the muscles, nerves, and sinews of the body. Following the logic of habitus, we could say that what propels such ritual practices are dispositions inculcated by early pedagogy that is part of a child's primary learning and constantly reinforced through socialization in a Jewish home. Thus having knowledge of the broche and the meaning of the menorah is akin to having acquired the mother tongue, in that the subject is unaware of the associated learning and is thus ignorant of all that is tacitly granted through socialization. In this respect, Jacob and Dora did not embark upon the practice of ritual as a conscious act, for they were born into the practice.

The emotion that is commonly expressed by Eastern European Jews in gesture and speech is similarly expressed in prayer through bodily movement and melody. In the Jewish faith, gestures, movements, and melody are essential ingredients in the life of prayer, enabling worshippers to put the whole of themselves into the act of worship (Jacobs 1972; Rosenberg 1997). On Simchat Torah, 
as Jacob prayed, he swayed deeply, stepping forward and back, bowing and striking his chest with clenched fists, his movements reflecting an intense and vital bodily force that is common in Jewish prayer. As he rejoiced with the Torah in dance he was highly enthusiastic, passionate, and emotional.

Following Bourdieu's thought, Jacob's movements are "learned" by the body, but it is not a kind of knowledge that one has; rather, it is "something that one is" (I990, 73; emphasis added). This means that what the body learns is never detached from the body; it is prereflective and thus can be activated only by its being evoked in practice. To be even more precise, it is a "practical reactivation" (73) whereby the knowledge that the body reproduces is not a memorization of the past but rather an enactment of it. Bourdieu refers to this knowledge as "practical sense" (69) that constitutes the world as meaningful by spontaneously anticipating its immanent tendencies (Bourdieu and Wacquant I992). As I have already argued, practical sense does not derive from rules, principles, or calculations, or from a premeditated goal, which, for Jacob, would in any case be excluded by the urgency or spontaneity of his actions. And in his case, reflective thought and calculation would be further excluded by the fact of his advanced dementia. Neither could Jacob's movements be mistaken for pure imitation, particularly if we consider that his precise and passionate recitation of the blessing before the bimah was a solo performance.

There is an apparent contradiction between Jacob's coherent performance in the synagogue and the fact of his cognitive impairment, manifested in his inability to speak coherently beyond monosyllabic utterances. This apparent contradiction can be resolved if we approach Jacob's ritual gesture as the application of a practical logic, produced without any conscious intention by a structured, structuring body that functions as a generator of a symbolic act. His prayer was not an intellectual effort of meditation and contemplation. Bourdieu would say that it is practical sense that, for Jacob, brought an instant appreciation of the meaning of being before the bimah and enabled him to produce at once the appropriate ritual gestures. That Jacob was in such command while standing before the bimah attests to Bourdieu's argument that schemes of perception, appreciation, and action are not only acquired through practice, but also implemented in a practical state in which objective structures match those of which the schemes of habitus are a product. Bourdieu argues that habitus and the way in which it shapes perceptions, motivation, and action dispose the subject to recognize and engage in particular practices, which in turn perpetuates one's system of dispositions (Bourdieu I990, 58-59). We can therefore understand Jacob's actions as being the result of the reactivation of his system of dispositions through involvement in a practice of similarly structured practices. The synagogue, its congregants, the presence of the rabbi, and the touch of the Torah scrolls were aspects of an organized event that exercised the pertinent incitement of the habitus. Jacob would not have succeeded in his performance 
at the bimah had there not been a concordance between the opportunity and the disposition to grasp it.

As long as one ignores the notion of a "conductorless orchestration" (59), that is, habitus as a spontaneity without consciousness or will, one is left with no other unifying principle than conscious coordination and, consequently, no reasonable explanation for the coherent performance of ritual practices in the face of severe cognitive impairment. On the basis of my argument that selfhood resides in sociocultural bodily dispositions, we could say that selfhood is what propels the reenactment of these ritual practices. To say that selfhood is the generator of ritual practice is to stress the body's prereflective capacity to express itself.

\section{Selfhood: Coherence and Improvisation}

We have seen in the discussion of the primordial source of selfhood that Merleau-Ponty's notion of bodily schema gives us a practical and inherent hold on our body and its relation to things in the world. I have suggested that we should think of Merleau-Ponty's notion of the perspectival unity of corporeal schema as providing the foundational structure for selfhood, a structure that itself consists in perception as embodied consciousness. Thus, fundamental to the coherence of selfhood is the unique totality achieved through the synthesis of movement and embodied perception, that is, through the body's ability to seize upon and transform the perceptible into something meaningful. The way that my study participants unthinkingly carried and projected their bodies disclosed a coherence and unity in their directedness toward the world. It is this unity that, at a fundamental level, allowed my participants to converse with the world, in grasping external space, as well as in mutuality with others. Hence my argument that bodily schema, the primordial unity of the body, is foundational to the coherence of embodied selfhood.

However, embodied selfhood owes its coherence not only to the foundational unity of the body, but also to the embodiment of culture-specific conditions of primary socialization. This is apparent when we consider the ongoing interactions of daily life at Chai Village, where there was coherence and consistency in the residents' mastery of their social world, in the ways that they embraced their daily routines and engaged in specific activities. The rhythm of ongoing interactions of daily life at Chai Village owed its regularity and predictability, its steadiness and persistence, to the objective structures that produced the dispositions of the residents and that continued to inform their interaction (Bourdieu I990, 59). As a result of the internalization of external structures, the residents of Chai Village were able to react to the demands of their environment in a coherent and systematic manner.

We could say that selfhood is their practical sense operating at the preobjective level and endowing their world with meaning. For example, there was 
a particular logic to the meal experience, an observable coherent, consistent intelligibility to my participants' management of the demands of this social activity. Such consistency, which is a precondition of the coordination of the meal as a practice, presupposes on the part of the residents a mastery of a common code that functions as a kind of self-regulating mechanism. Thus, there is an immediate familiarization with, for example, the proper use of utensils, napkins, salt and pepper, and butter and jam. Furthermore, when the residents sit at the table they socialize with one another and, for the most part, respect table etiquette while they eat their meal. In other words, there is a harmony between practical sense and the socially objectified meaning of sitting at the diningroom table that creates a consensus in the meaning of the practice (Bourdieu I990, 58). Their manner of interacting with one another at the table and the competencies that they clearly embody are what Bourdieu refers to as "a harmonization of the agents' experiences" that results from the homogeneity of conditions of existence. That is, their social history and culture are objectified in habitus, which harmonizes practices without any deliberate pursuit of coherence or conscious reference to a norm, and without any explicit coordination (58-60). We know that there is no explicit coordination through cognition because, to continue with the example of a meal, there were no two lunches, dinners, or breakfasts that were identical in terms of the interactions that transpired, thus militating against any notion of advanced orchestration or mechanical repetition. This suggests that practices are regulated without being the product of obedience to external rules because the taken-for-granted, prereflexive nature of practices flows from embodied selfhood.

Mastery of a common code was evident not only where there was regularity in social practice, but also when something happened that deviated from or contradicted the common code, such as when a resident who failed to adhere to proper etiquette was met with strong disapproval from others. For example, Abe, one of my participants, belched loudly in the dining room and Anna held her hands over her ears, yelling, "Tell the meshugener, stop it," in an indication that Abe's behavior was offensive to her. Anna's reaction can be interpreted as a negative sanction because Abe's behavior was too different from what she expected and from that to which she had objectively adjusted. As Bourdieu argues, "[H]abitus tends to favour experiences likely to reinforce it . . . to protect itself from crises and critical challenges by providing itself with a milieu to which it is as pre-adapted as possible" (I990, 6I; emphasis in original). A similar disjunction between habitus and objective conditions occurred when Molly furrowed her brow and abruptly stopped eating when she saw Dody, who was sitting directly in front of her, using the twisted corner of a napkin to clean her nostrils. The behavior of Abe and Dody was deemed improper and intolerable, attesting to the persistence of embodied selfhood. Put simply, behavior is negatively sanctioned when it offends the sensibility of one's selfhood. 
The disjunction between habitus and objective conditions that the preceding examples reveal points to a central objective of Bourdieu's work, which is to show how cultural practices are markers underlying class distinctions. Since habitus produces practices adjusted to the regularities of the conditions of existence, taste and etiquette, according to Bourdieu, are markers of social orientation and thus provide a "sense of one's place" (I984, 466). For example, the class distinctions between the residents of Chai Village, at the corporeal level, is evident if we consider that Dora's polyester dresses and plastic shoes would never be confused with the elegant silk blouses, slacks, and low pumps favored by Molly. Similarly, Anna's oversized, tarnished Star of David is in marked contrast to the refined, pure white pearls that adorn Molly.

However, it is not jewelry and garments alone that distinguish residents from one another; differences can also be gleaned through social etiquette and physical manner. Edna is aggressive and boastful, characteristics that are in marked contrast to Dody's propriety and modesty and her general objections to the indecorous, even brazen manner of Edna. There is an excessive swing of the hips that comes from Edna's heavy stride and even when seated there is a constant movement of her hands and feet. In contrast, when Molly walks her steps are delicate, and when she is seated, her legs are always crossed and her hands clasped in her lap. Molly's delicate manner is also apparent when she uses a paper tissue, softly wiping the tip of her nose, whereas Edna, in contrast, blows sharply and loudly, covering her entire nose and clenching it tightly with the tissue. When eating, Goodie is prone to putting large portions of food into her mouth at one time, using her hands as much as she does her utensils, and will invariably drop food down her front. Molly delicately puts food between her lips with reserve and restraint, always being careful not to get stains on herself.

All these propensities and movements of the body are socially qualified. This is so because, according to Bourdieu, each habitus embodies both the material conditions of existence of a class and the symbolic differentiations that categorize and rank its relation to other classes. Individuals are then predisposed to make lifestyle choices characteristic of their class habitus (I984, I72). Molly's refined clothing, jewelry, and table etiquette, in contrast to the aggressive, brash behavior of Edna, clearly are reflective of her different social origin. We see in the preceding examples a practical expression of class distinction, and to this extent, there is a practical equivalence between the different divisions of the social world and selfhood.

The class distinctions between the residents of Chai Village should not obscure the fact that the totality of each participant's manifestations of selfhood discloses internal consistency and coherence such that all manifestations are congruous with and representative of the particular social class of the individual. This is apparent when we consider, for example, the connection between Molly's wearing her pure white pearls; crossing her legs and clasping her 
hands in her lap when seated; delicately placing food between her lips with reserve and restraint, always exercising care not to let food fall on herself; and finally, politely using her tissue to wipe the tip of her nose. There is a similar connection between Edna's excessively swinging her hips while walking; aggressively salting her food; loudly blowing her nose while covering her entire face with a tissue; and wearing a pedestrian style of dress, demonstrated by her loose-fitting sweaters and dated costume jewelry.

Coherence in the distinctiveness of embodied selfhood is not confined to bodily expressions of social class. Distinctiveness is also evident when we consider how spontaneity, and the ability of the residents of Chai Village to go with the inspiration of the moment, produced diverse practices that were relatively unpredictable, just as were their corresponding situations. The residents have the use of their bodies not only insofar as they are involved in a concrete setting but also to affect actions that go beyond the specificity of concrete tasks such as sipping a cup of coffee or removing one's shoes at the end of the day. Dora, for example, sang on her own accord; Edna often stopped to look at the paintings on the wall while strolling down the hallway; and Anna would glance at her wedding band and engagement ring while quietly sitting alone. There was spontaneity in the residents' openness to situations, whether this was of their own accord or prompted by others. Abe slow danced to a song playing on the radio with a health-care aide when prompted to take her hand; and when a Styrofoam ball was playfully tossed to Anna, she threw it back. In all these instances, the body puts forth beyond itself meanings that can be read as providing a framework for a whole series of experiences. In this regard, selfhood does not reside in organic processes but in human gestures and movements that issue from these processes. This is most apparent when we consider that the preceding examples are incomprehensible if selfhood is treated as a machine governed by natural laws, or even as a cluster of instincts.

The examples render visible how selfhood emanates from the body as a generative spontaneity that asserts itself in an improvised engagement with the world. The idea emphasized here is that the engagement of the self with the world consists primarily in the residents' intrinsic corporeality of being-in-theworld. This implies that self is grounded in the prereflective level of experience, providing "practical sense" (Bourdieu I990) or "practical competence" (Merleau-Ponty 1962) for the residents to engage with the world. Selfhood animates their presence and endows with coherence and spontaneity their interactions with the world.

\section{Conclusion}

In the literature on Alzheimer's, the implicit reference to a presumed loss of agency is a product of the Western assumption that only the mind relates us to 
the world and gives it meaning, rendering silent and inconsequential the lived materiality of the body. Central to this perspective on the body is a concept of personhood that hinges exclusively on cognition and rationality, ignoring the significance of Merleau-Ponty's bodily schema and Bourdieu's notion of habitus. However, as I have argued, following Merleau-Ponty and Bourdieu, the existential and social aspects of the body are indispensable to the articulation of selfhood. The coherence of selfhood and its generative spontaneity reside in our embodiment, which is a synthesis of primordial and social being. It is an argument that challenges the current conviction that selfhood is tied exclusively to cognition, by treating the body as a primary source of selfhood and a facilitator of its articulation. This is not to suggest that the prereflexive body exhausts selfhood; however-and this is the crucial point-even if the residents of Chai Village were not as cognitively impaired as they were, or not impaired at all, still the prereflexive body would continue to be fundamental to the whole of their selfhood.

Although embodied selfhood is a concept I use to articulate and theorize findings drawn from a particular ethnographic setting, it is a concept that invites inference of larger scope. This is because, as I have argued, the primordial unity of the body as well as specific sociocultural dispositions, all of which sustain the self at a prereflective level, are fundamental to our existential being. In other words, the interrelationship of the primordial body, sociocultural bodily dispositions, and selfhood transcends cultural distinction. This is not to suggest that selfhood would manifest itself in uniform or identical fashion irrespective of the sociocultural context. On the contrary, the sociocultural specificity of selfhood, as expressed in one's habitual state and in one's tendencies and inclinations to act in a particular way, would be different from culture to culture. However, it is for further ethnographic research to explore what these differences are and what they mean in the context of the interrelationship between selfhood, the primordial unity of the body, and specific sociocultural bodily dispositions. Embodied selfhood by no means concludes the matter of body-self, body-world relations; nor is it intended to resolve the debate about the self in Alzheimer's disease. Thinking of selfhood as embodied provides new insight and direction for future investigation of the localized symbiosis of prereflective intentionality and structures of the social world. It is a symbiosis that is "enacted at every instant in the movement of existence" (Merleau-Ponty I962, 89), rendering the animated, living, experiential body as of paramount importance for understanding the nature of human agency, selfhood, and embodiment.

\section{NOTES}

I would like to gratefully acknowledge financial support provided by the Alzheimer's Society of Canada and the Institute of Aging (Canadian Institutes of Health Research), Award 03 07. I also wish to thank Ann Robertson and Stephen Katz for their constructive and insightful comments on an earlier draft of this chapter. 
I. The name of this facility is a pseudonym.

2. Cognitive impairment was measured with the Mini Mental State Examination (MMSE), a widely used method for assessing cognitive mental status (Folstein, Folstein, and McHugh 1975). Within my sample of study participants, the mean MMSE score was II.3 and the range was I-I5 (mild, I9-24; moderate, IO-I8; severe, O-IO) (Jones et al. 2004). MMSE scores have not been adjusted to remove the effect of age and education, which are said to be of etiological significance in dementia (Crum et al. 1993). However, by virtue of the fact that all participants resided on a secured Alzheimer's Support Unit because of the degree of their cognitive impairment, even if scores were adjusted for age and education, the adjustment would not have altered in a meaningful way their assessed degree of cognitive impairment.

3. The names of residents living in Chai Village, as well as any names of Chai Village staff referred to throughout this chapter, are pseudonyms.

4. Bodily discourse has played a significant role in the history of anti-Semitism, with claims of there being a differentiated Jewish body (for a discussion, see Gilman I99I). My analysis is in no way an attempt to essentialize a primordial Jewish set of bodily characteristics. On the contrary, I am demonstrating how the culture-specific conditions of socialization become, for my study participants, an important resource for bodily expressions of their selfhood.

\section{REFERENCES}

Bourdieu, Pierre. 1977. Outline of a Theory of Practice. Trans. R. Nice. Cambridge, U.K.: Cambridge University Press.

—. 1984. Distinction: A Social Critique of the Judgement of Taste. Trans. R. Nice. Cambridge, Mass.: Harvard University Press.

—. 1990. The Logic of Practice. Trans. R. Nice. Cambridge, U.K.: Polity Press.

Bourdieu, Pierre, and Loïc Wacquant. 1992. An Invitation to Reflexive Sociology. Chicago: University of Chicago Press.

Cohen, Donna, and Carl Eisdorfer. 1986. The Loss of Self: A Family Resource for the Care of Alzheimer's Disease and Related Disorders. London: W. W. Norton.

Crum, Rosa, James Anthony, Susan Bassett, and Marshal Folstein. 1993. "Population-Based Norms for the Mini-Mental State Examination by Age and Educational Level." Journal of the American Medical Association 269 (I8): 2386-239I.

Davis, Daniel. 2004. "Dementia: Sociological and Philosophical Constructions." Social Science and Medicine 58:369-378.

Dalziel, William. 1994. "Dementia: No Longer the Silent Epidemic." Canadian Medical Association Journal I5I (IO): I407-I409.

Efron, David. 1972. Gesture, Race, and Culture. The Hague: Mouton.

Folstein, Marshal, Susan Folstein, and Paul McHugh. 1975. "Mini-Mental State: A Practical Method for Grading the Cognitive State of Patients for the Clinician.” Journal of Psychiatric Research 12:196-I98.

Fontana, Andrea, and Ronald Smith. 1989. "Alzheimer's Disease Victims: The 'Unbecoming' of Self and the Normalization of Competence." Sociological Perspectives 32 (I): 35-46.

Gilman, Sander. 199I. The Jew's Body. New York: Routledge.

Herskovitz, Elizabeth. 1995. "Struggling over Subjectivity: Debates about the 'Self' and Alzheimer's Disease.” Medical Anthropology Quarterly 9 (2): I46-I64.

Jacobs, Louis. 1972. Hasidic Prayer. London: Routledge.

Jones, R., H. Soininen, K. Hager, D. Aarsland, P. Passmore, A. Murthy, R. Zhang, and R. 
Bahra. 2004. "A Multinational, Randomised, I2-Week Study Comparing the Effects of Donepezil and Galantamine in Patients with Mild to Moderate Alzheimer's Disease." International Journal of Geriatric Psychiatry 19:58-67.

Kitwood, Tom, and Kathleen Bredin. 1992. "Towards a Theory of Dementia Care: Personhood and Well-Being." Ageing and Society 12:269-287.

Kontos, P. 2003. “'The Painterly Hand': Embodied Consciousness and Alzheimer's Disease.” Journal of Aging Studies I7:I5I-I70.

Merleau-Ponty, Maurice. 1962. Phenomenology of Perception. Trans. C. Smith. London: Routledge and Kegan Paul.

—_. I964. "An Unpublished Text by Maurice Merleau-Ponty: A Prospectus of His Work." In The Primacy of Perception, ed. J. Edie. Evanston: Northwestern University Press.

Mills, Marie, and Janet Walker. 1994. "Memory, Mood and Dementia: A Case Study." Journal of Aging Studies 8 (I): 17-27.

Robertson, Ann. 199I. "The Politics of Alzheimer's Disease: A Case Study in Apocalyptic Demography." In Critical Perspectives on Aging: The Political and Moral Economy of Growing Old, ed. M. Minkler and C. L. Estes. Amityville, N.Y.: Baywood.

Ronch, Judah. 1996. "Mourning and Grief in Late Life Alzheimer's Dementia: Revisiting the Vanishing Self." American Journal of Alzheimer's Disease II (4): 25-28.

Rosenberg, Arnold. 1997. Jewish Liturgy as a Spiritual System. Northvale, N.J.: Jason Aronson.

Schroeder, Steven, Marcus Krupp, Lawrence Tierney, and Stephen McPhee. 1990. Current Medical Diagnosis and Treatment. Norwalk, Conn.: Appleton and Lange.

Wacquant, Loïs. 1992. "Toward a Social Praxeology: The Structure and Logic of Bourdieu's Sociology." In An Invitation to Reflexive Sociology, ed. P. Bourdieu and L. Wacquant. Chicago: University of Chicago Press. 